\title{
Impacto de la construcción de la Terminal de Contenedores (APM Terminals) en Playa de Moín, Costa Rica
}

\author{
Impact of the construction of the Container Terminal (APM \\ Terminals) in Moín Beach, Costa Rica
}

\author{
Annie Vargas-Hernández ${ }^{1}$ \\ Ministerio de Ambiente y Energía, Costa Rica \\ Gustavo Barrantes-Castillo ${ }^{2}$ \\ Universidad Nacional, Costa Rica
}

\begin{abstract}
Resumen
Esta investigación basó su análisis en el efecto que ha tenido la construcción de la Terminal de Contenedores de Moín (TCM) sobre la playa entre desde el inicio de la obra y hasta 2017. El impacto fue determinado en términos de su efecto sobre los cambios en la línea de costa y el perfil de la playa. Los resultados muestran que ya existía un retroceso de la línea de costa, anterior a la construcción de la obra, que se ha extendido con la obra y que los mayores cambios son debido a la interrupción de las corrientes de transporte de sedimento y al engorde artificial de la playa, en las proximidades de la obra.
\end{abstract}

Palabras clave: terminal de contenedores de Moín, playa Moín, erosion costera.

\begin{abstract}
This research is based the analysis that the effect that the construction of the Container Terminal of Moín (TCM) had on the beach from the beginning of the work until 2017. The impact is determined by the effects on changes in the coastline and the profile of the beach. The results showed a regression of the coastline before the construction, which has been extended with the TCM and that

1 Licenciada en Geografía, Secretaría Técnica Nacional Ambiental, Ministerio de Ambiente y Energía. Correo electrónico: avahe08@gmail.com

2 Doctor en Ciencias Naturales. Académico e investigador en Escuela de Ciencias Geográficas, Universidad Nacional, Costa Rica. Correo electrónico: gustavo.barrantes.castillo@una.cr
\end{abstract}

Este artículo corresponde a la ponencia presentada en el 35th Conference of Latin American Geographers realizada en San José, Costa Rica del 20 al 22 de mayo del 2018 
the biggest changes are due to the interruption of the sediment transport currents and the artificial accretion of the beach, in the vicinity of the TCM.

Keyword: container terminal of Moín, Moín beach, coastal erosion

\section{Introducción}

Playa Moín se encuentra en la provincia de Limón, en el cantón y distrito central. De acuerdo con el Centro Científico Tropical (2013), desde el punto de vista geológico, esta zona está conformada por material sedimentario procedente de la formación Limón. La geología local se compone por depósitos cuaternarios, ésta incluye materiales de origen marino y aluvial producto de los procesos fluviales y la acción del mar sobre las rocas y arrecifes, que sufrieron un levantamiento costero, los materiales que se pueden encontrar entre la playa y el río Moín son arenas finas con algo de grava, arena limosa y limos.

En el año 2015, la Terminal de Contenedores de Moín (de ahora en adelante TCM) APM Terminals inicia su construcción y como es de esperar y se evidencia una transformación del espacio que afecta tanto a las especies endémicas, como a la dinámica de playa en Moín.

\section{Metodología}

La investigación se dividió en dos momentos claves: un estudio anterior a los inicios de la obra y durante este proceso. En la primera parte se levantaron las líneas de costa de playa Moín en imágenes satelitales disponibles en Google Earth para los años 2010, 2014 y 2017, a partir del proxi de la línea húmedo-seco.

En cuanto al análisis de la playa, se realizó un trabajo de campo que consistió en el levantamiento de perfiles de playa que permitieron caracterizar la morfología y monitorear la playa, en busca de relaciones entre la construcción de la TCM y procesos de erosión costera en playa Moín.

Previo al levantamiento de los perfiles, se requirió de una logística que incluyó la definición de las fechas óptimas para llevar a cabo la recolección de datos. Para ello, fue necesario definir cuatro fechas, distribuidas en las diferentes estaciones del año, cuya selección del día estuviera próxima a la fase lunar del cuarto menguante o del cuarto creciente, ya que en estas fases se presentan las menores mareas. 


\section{Resultados}

- $\quad$ Cambios en la línea de costa entre el 2010-2017

La calidad en la resolución espacial de las imágenes disponibles en esta plataforma llevó a la selección de tres imágenes que corresponde con: 2010, 2014 y 2017. Por consiguiente, el periodo de análisis abarca siete años.

Con base en las imágenes seleccionadas se levantó la línea de costa para cada año, haciendo uso de la línea húmedo-seco como proxi de esta (Boak y Tunner, 2005, p.690). En el mapa 1 se pueden apreciar las líneas de costa trazadas para esta investigación. La línea correspondiente al año 2010, representada en color naranja, se trazó en una imagen captada el 01 de agosto. Por su parte, la línea de costa para el año 2014 se representa con el color morado y fue tomada el 21 de diciembre del 2014. Finalmente se utilizó el color celeste para representar la línea de costa del 17 de diciembre del 2017.

Para facilitar el análisis de los cambios el área fue dividida en tres secciones en función del comportamiento de la línea de costa antes de la construcción de la obra, en la sección A la línea de costa experimenta pocos cambios con tendencia al avance, en la sección $\mathrm{B}$ se registra un retroceso y en la sección $\mathrm{C}$ de da un avance).

En la sección A, entre el 2010 y el 2014 se visualiza un ligero avance de la línea de costa. En este periodo, anteriores a la construcción de la obra, se obtuvo un avance máximo de $20 \mathrm{~m}$ aproximadamente, para una tasa media de 10 m/años. En cuanto al año 2017, se observa una acreción de la playa que se atribuye al impacto antrópico provocado por la construcción de la nueva TCM. La prolongación máxima de la playa entre el 2014 y el

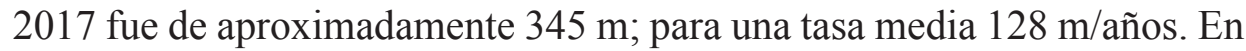
campo se constató que la gran mayoría de este avance se realizó en cuestión de meses por el vertido artificial de sedimento en 2017. 
Mapa 1. Líneas de costa y ubicación de perfiles de playa

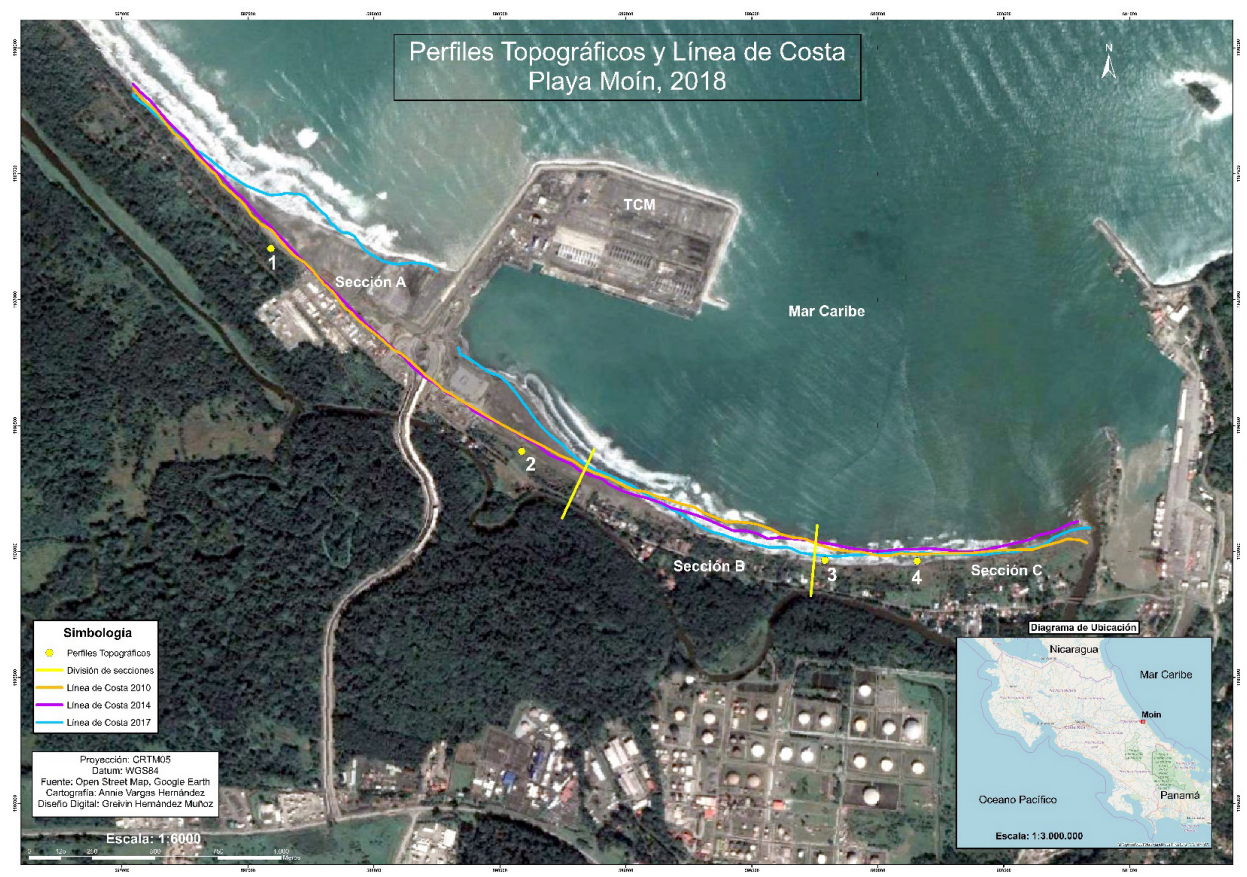

Fuente: datos levantados en el trabajo de campo. Imagen tomada de Google Earth Pro.

En la sección B, la línea de costa, entre el 2010 y el 2014, presenta un

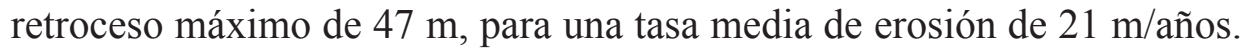
Mientras que la regresión máxima entre el 2014 y el 2017 es próxima a los $55 \mathrm{~m}$, para una tasa media de erosión de $35 \mathrm{~m} / \mathrm{años}$. El retroceso de la playa aumenta con la construcción de la TCM, lo anterior se evidencia en el campo (Fotografía 1) con la construcción de obras contra la erosión costera por parte de la empresa. 
Annie Vargas-Hernández, Gustavo Barrantes-Castillo. Impacto de la construcción de la Terminal de Contenedores (APM Terminals) en Playa de Moín, Costa Rica

Fotografía 1. Obras de mitigación contra la erosión costera, playa Moín, 2017

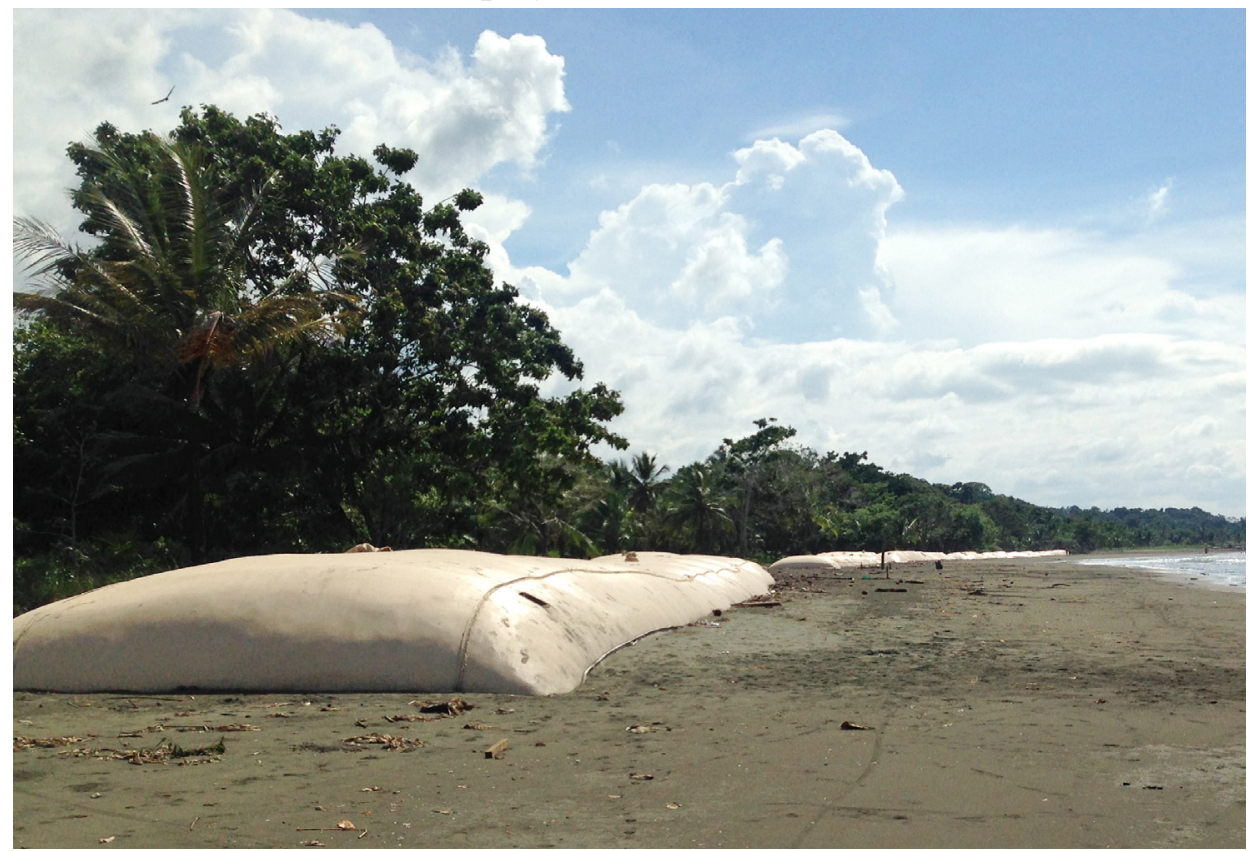

Fuente: Fotografía tomada por Gustavo Barrantes durante trabajo de campo

Con respecto a la sección $\mathrm{C}$, antes de la construcción de la TCM, entre el año 2010 y el 2014, se presenta una acreción menor de la playa de acuerdo con la línea de costa, que representa un máximo de $68 \mathrm{~m}$, con una tasa media de $26 \mathrm{~m} / \mathrm{años}$. Al comparar la línea de costa entre 2014 y 2017 se obtiene un retroceso máximo de $53 \mathrm{~m}$; con una tasa media de $29 \mathrm{~m} / \mathrm{años}$.

- Cambios en la playa Moín

Se programaron dos giras en la época de mayor pluviosidad (diciembre y junio) y otras dos en la época de menores precipitaciones (marzo y setiembre), esto con el fin de estudiar el comportamiento de la dinámica de playa con diferentes condiciones climáticas

Se definieron cuatro puntos de monitoreo a lo largo de playa Moín para el levantamiento de los datos. Estos puntos se precisaron en el campo mediante la observación y criterio profesional del grupo de trabajo. 
La técnica fue levantamiento de perfiles por medio de nivel topográfico. En cada punto se levantó un perfil topográfico, con el fin de monitorear los cambios experimentados en el periodo de estudio y se tomaron muestras de arena. Además, se recolectó información adicional sobre el comportamiento del mar.

Mapa 3. Playa Moín, ubicación de Perfiles topográfico

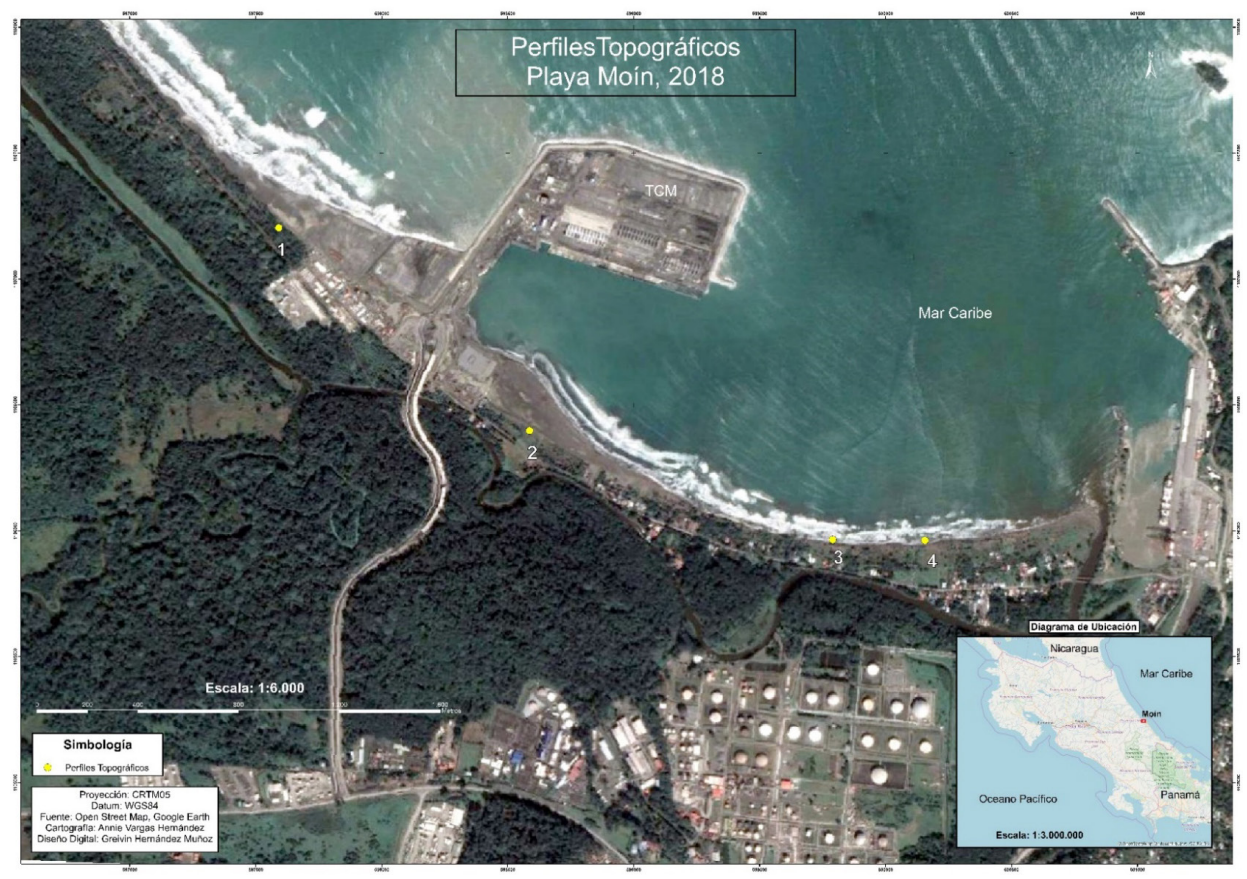

Fuente: datos levantados en el trabajo de campo. Imagen tomada de Google Earth Pro.

- $\quad$ Perfil topográfico 1

En diciembre del 2016 la longitud del perfil fue de 58,5 m; para marzo del 2017, la longitud total fue de 123,31 m; mientras que para junio del 2017 la distancia de medición disminuye nuevamente a 78,88 m; tal y como se observa en la figura 1. 
Figura 1. Perfil topográfico 1
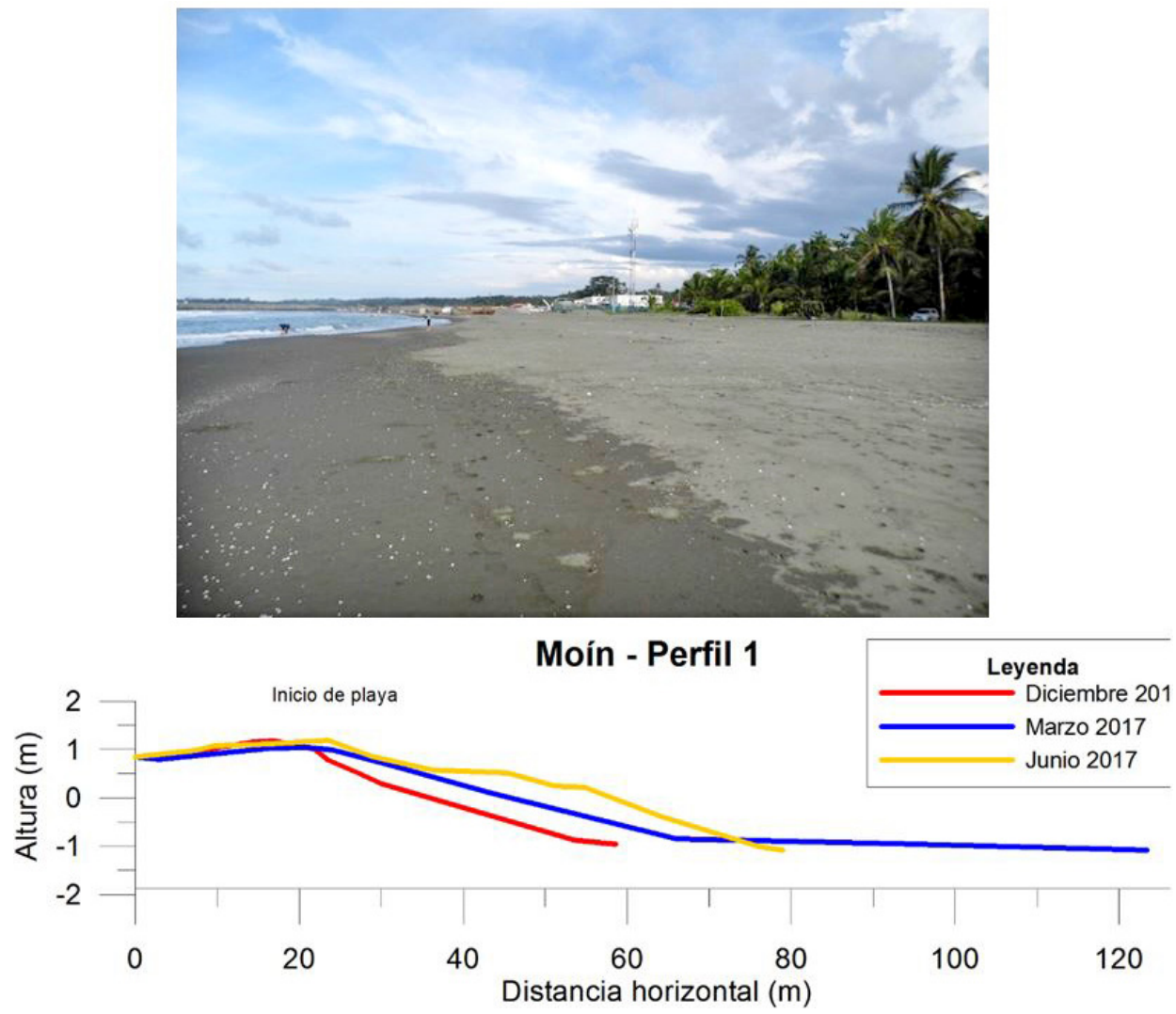

Fuente: Fotografía del área del perfil tomada por Gustavo Barrantes durante trabajo de campo

El comportamiento del perfil 1 se puede observar un patrón de acreción de la playa entre las mediciones. Diciembre es un mes que se encuentra bajo la influencia de los vientos alisios, por ende, se puede atribuir a este fenómeno el hecho de que la línea de costa esté a menor distancia (30 $\mathrm{m})$, debido a que el oleaje en esta época del año posee más energía, por lo que produce erosión. Caso parecido sucede para el mes de marzo $(43,41$ $\mathrm{m})$, que también recibe influencia de este elemento climático.

Por su parte, el perfil levantado en junio del 2017 es el que presenta la línea de costa a una mayor distancia $(64,08 \mathrm{~m})$, recordando que este es el mes que muestra menor energía en cuanto oleaje se refiere, debido a la disminución de los vientos alisios en la región Caribe. 
De acuerdo con el comportamiento del perfil 1, podría deducirse que esta sección de playa Moín sufre acreción producto de la deriva litoral, la corriente hace un aporte considerable de sedimentos que se evidenciaban en cada medición.

Desafortunadamente, para el mes de setiembre del 2017 no fue posible realizar el levantamiento del perfil, ya que la playa fue artificialmente alterada por las obras en la TCM, donde se realizaba un relleno de la playa.

\section{- $\quad$ Perfil topográfico 2}

El perfil 2 es el único que se localiza frente a la obra de la TCM, por ende, presenta más alteración antrópica.

La longitud total del perfil para diciembre del 2016 fue de $126 \mathrm{~m}$; para marzo del 2017 la distancia total fue de 142,29 m; en junio del 2017 la extensión de medición fue de 149,52 m y para setiembre del 2017 la amplitud total fue de $158,83 \mathrm{~m}$. En la figura 2, se observa como el perfil 2 creció en extensión a lo largo del monitoreo.

Figura 2. Perfil topográfico 2
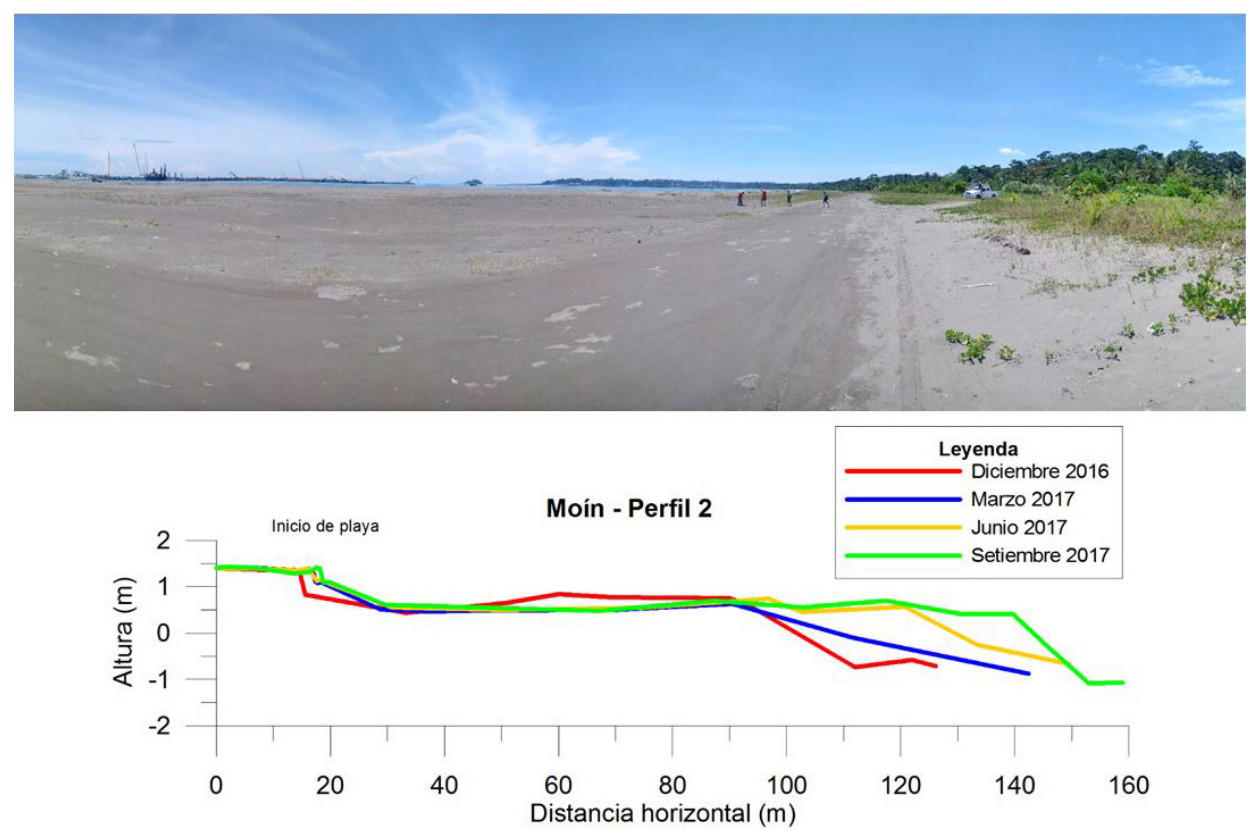

Fuente: Fotografía del área del perfil tomada por Gustavo Barrantes durante trabajo de campo 
Este perfil constantemente ha mostrado una acumulación de sedimentos debido a las condiciones específicas en las que se encuentra, el ensanchamiento de la playa en esta sección se debe principalmente a la alteración antrópica ocasionada por la construcción de la obra, aunque no se puede dejar de lado la acción del oleaje que se encuentra diezmado por la zona de sombra que se constituye en este sector por la isla artificial.

Por ejemplo, en diciembre del 2016 la línea de costa se encontraba a 93,2m de distancia y en marzo del 2017 la línea de costa se hallaba a 111,59 m de distancia; la diferencia entre ambas mediciones fue de aproximadamente 18 metros, en cuestión de tres meses, la playa se acrecentó considerablemente. Asimismo, entre marzo y junio, cuya distancia fue de $133,42 \mathrm{~m}$, la línea de costa se incrementó cerca de 21 metros, aumentando en aproximadamente tres metros la distancia entre líneas de costa con respecto al periodo anterior.

Entre junio y setiembre $(145,39 \mathrm{~m})$ la distancia entre ambas líneas de costa fue alrededor de 12 metros. Se sigue una línea similar al perfil anterior, donde los meses con mayor energía de oleaje, diciembre y marzo, son los que presentaron menor longitud con respecto a la línea de costa, y que la misma se incrementa mayormente en los meses con menor oleaje (junio y setiembre).

Es posible afirmar que la TCM representa una barrera artificial que está atrapando los sedimentos que ingresan al noroeste de la obra, al cortar las corrientes litorales que transportan los sedimentos, por consiguiente, el ensanchamiento de la playa en este sector está relacionado con el aporte artificial de sedimentos y el abrigo al oleaje que representa la obra. Asimismo, al observar la dirección del oleaje en las imágenes recientes se nota que el sedimento que fue retirado del sector central de la playa ha sido trasportado a este sector que se encuentra próximo a la obra.

\section{- $\quad$ Perfil topográfico 3}

En la figura 3, se puede observar como las longitudes del perfil topográfico 3 varían considerablemente, las mismas se establecen de la siguiente manera: para diciembre fue de $59,45 \mathrm{~m}$; en marzo la longitud total fue de 97,16 m siendo el más largo, en junio la extensión del perfil fue de $63,1 \mathrm{~m}$ y en setiembre la distancia total fue de $54,88 \mathrm{~m}$. 
A simple vista, si se detalla bien en el gráfico del perfil topográfico 3, se puede observar un retroceso en la playa desde diciembre del 2016 hasta setiembre del 2017.

Figura 3. Perfil topográfico 3
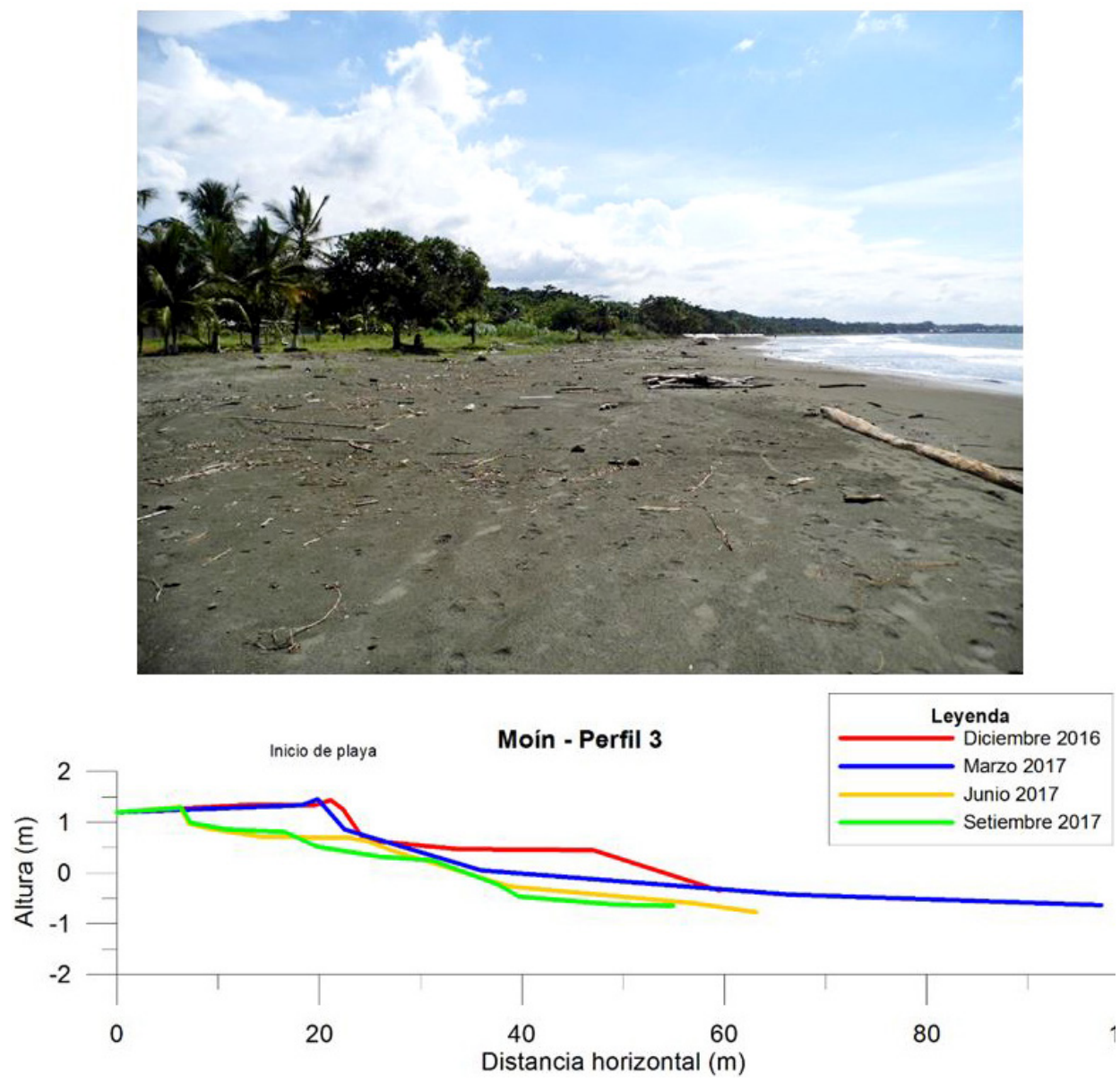

Fuente: Fotografía del área del perfil tomada por Gustavo Barrantes durante trabajo de campo

En cuanto a los datos de la línea de costa, en diciembre del 2016 la misma se encontraba a 47,05 $\mathrm{m}$ de distancia con respecto al punto de inicio del perfil. Para marzo del 2017, la línea de costa se encontraba a $35,96 \mathrm{~m}$, es decir, hubo una disminución aproximada de $11 \mathrm{~m}$. Es un retroceso significativo que no se recuperó en el periodo de monitoreo de esta 
investigación. No obstante, es importante señalar que, en apariencia, la TCM influye en este retroceso de la playa, ya que la obra representa una barrera que está obstaculizando la llegada de sedimentos en esta sección.

Para junio del 2017 la línea de costa se extendió hasta los 38,8 m; mes en que los vientos alisios disminuyen considerablemente, es concordante entonces la extensión de casi tres metros entre marzo y junio debido a este factor. Sin embargo, en setiembre del 2017 la línea de costa retrocede a 37,63 m; cuando se debería esperar un incremento de los sedimentos por la disminución en la energía del oleaje. Evidentemente, la TCM está impidiendo el ingreso de nuevos sedimentos, lo que puede estar provocando un proceso de erosión costera.

También es interesante analizar en este perfil el punto de referencia del escarpe de berma, que marca el inicio de la playa, identificada en campo. Entre diciembre del 2016 y marzo del 2017 la regresión del escarpe de berma fue de aproximadamente metro y medio, sin embargo, entre marzo y junio la reducción de esta estuvo por encima de los 13 metros, manteniéndose hasta septiembre. Además, llama la atención que justamente en los meses donde la energía del oleaje es menor, sea precisamente donde se registra la mayor pérdida de sedimentos.

Si a los resultados de los datos se suma lo observado en campo, parece ser que este segmento de playa Moín está sufriendo un proceso de erosión costera, ya que cercano al punto del perfil se identificaron obras para mitigar el impacto de la erosión.

\section{- Perfil topográfico 4}

Para el perfil topográfico 4, la extensión total fue de 53,2 m para el mes de diciembre, en cuanto a marzo la longitud del perfil alcanzó los 69,16 m mientras que para junio aumentó a 77,18 metros y en setiembre disminuyó la extensión a 70,12 m.

En la figura 4 se observó un patrón interesante, entre diciembre del 2016 y marzo del 2017 se da un retroceso de playa Moín en este sector, mientras que para junio y setiembre se recupera considerablemente. 
Figura 4. Perfil topográfico 4
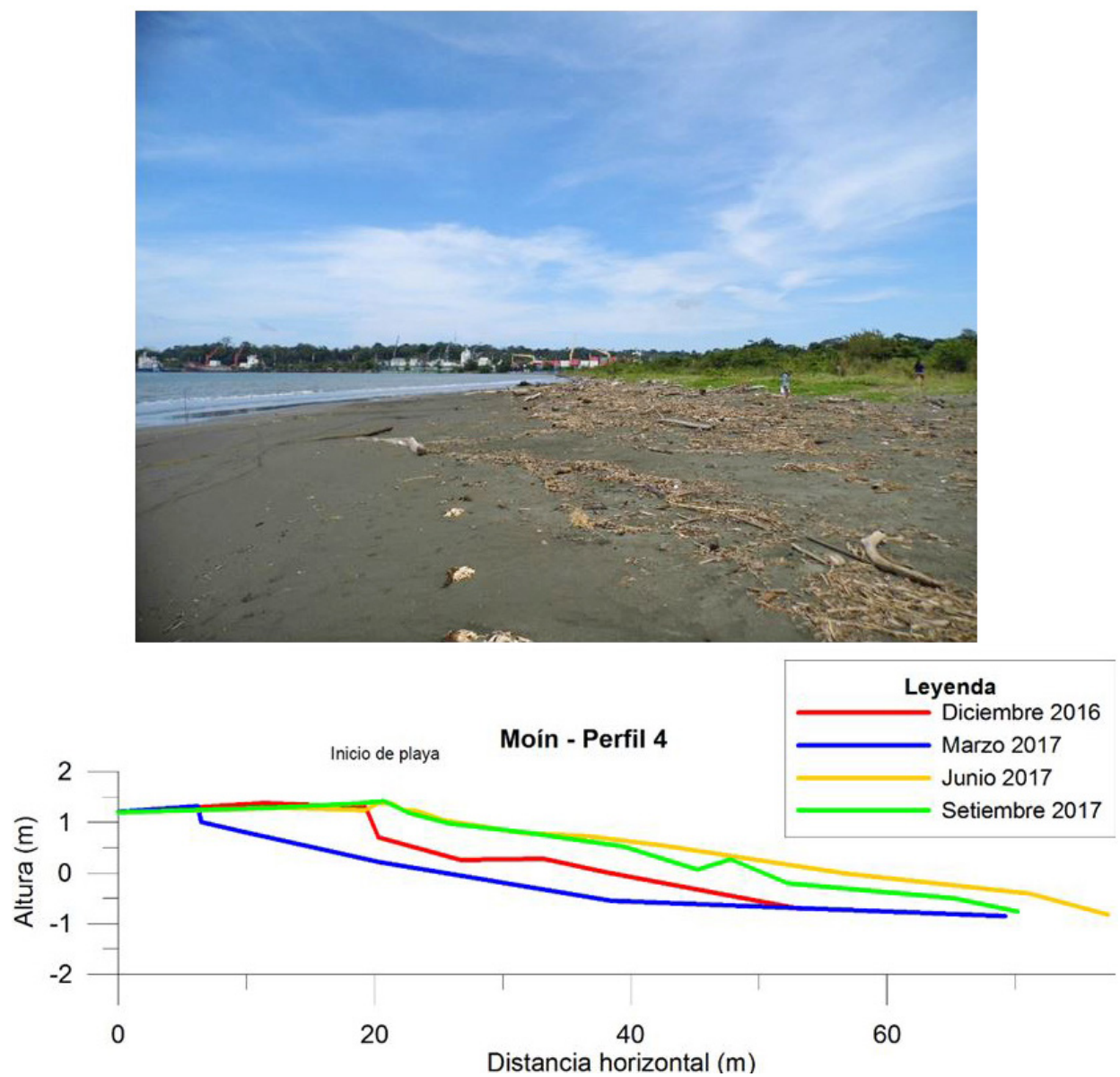

Fuente: Fotografía del área del perfil tomada por Gustavo Barrantes durante trabajo de campo

En cuanto al análisis de la línea de costa, esta retrocede en aproximadamente 18 metros entre diciembre (distancia de $38 \mathrm{~m}$ ) y marzo (distancia de 20,32 m), que se podría aludir a que en este periodo la acción del oleaje fue bastante fuerte, lo que provocó el transporte de sedimentos, así como al empuje frío que afectó en esas fechas.

Por su parte, la línea de costa para junio se extiende hasta los 56,82 $\mathrm{m}$; es decir, se obtuvo un incremento cercano a los $36 \mathrm{~m}$. La disminución en la energía del oleaje de este mes favoreció la acumulación de sedimentos. 
Se registra una recuperación de la playa a lo largo del periodo de monitoreo, que bien podría atribuirse a un proceso de dinámica de playa, ya que como se detectó en el apartado de la línea de costa, este es un sector donde se presenta tanto la prolongación como la regresión de la playa.

\section{Conclusiones}

Existe un riesgo por erosión costera en playa Moín, que se intensificó con la construcción de la TCM.

- $\quad$ El punto uno y dos presentan una acreción artificial de la playa.

- $\quad$ El punto tres, muestra señales de erosión costera que se apoyan con el comportamiento de las líneas de costa.

- La playa en el punto cuatro se extiende y regresa siendo un proceso de dinámica de playa.

- Trasformación de la forma de la playa en respuesta a la barrera que representa la obra al movimiento natural de los sedimentos.

- $\quad$ Agravamiento de los procesos de erosión que existían previamente a la construcción de la obra.

- Construcción de obras para contener la erosión con un fuerte impacto visual.

- $\quad$ Alteración de la playa por deposición artificial de sedimentos.

- Escenario de alta amenaza por el proceso de erosión costera y la cercanía con el meandro del río Moín.

\section{Referencias}

Boak, E. \& Turner, I. (2005). Shoreline definition and detection: a review. Journal of Coastal Research, 688-703.

Centro Científico Tropical. (2013). Estudio de impacto ambiental: Proyecto Terminal de Contenedores de Moín. Expediente $N^{\circ} 7968-12-S E T E-$ NA. San José, Costa Rica. 
